\title{
Analysis of Staff Performance System at Enterprises
}

\author{
Weijuan $\mathrm{Wu}$ \\ (Ji'an College, Ji'an, 343000)
}

\begin{abstract}
Keywords: Small and medium-sized private enterprise; Performance assessment; Analytic hierarchy process
\end{abstract}

\begin{abstract}
With the improvement of market economic system and the deepening reform of labor and personnel system, human resource management and its concept have been widely accepted, and staff performance assessment is the key and foundation of human resource management. Staff training and position placement should be based on staff performance assessment; staffs' performance evaluation and reward should be based on staffs' performance assessment. Traditional performance evaluation methods have many limitations, such as neglecting the process but focusing on the result, subjective evaluation cannot reflect the fairness of staff performance assessment, etc. Therefore, for enterprises, the importance of staff performance assessment is self-evident, but whether the staff performance assessment system is consistent with the actual needs of the enterprise is a problem that should be solved urgently. This paper mainly proposes methods to modify the current staff performance assessment at small and medium-sized enterprises, analyzes and concludes methods to improve staff performance assessment.
\end{abstract}

\section{Introduction}

With the development of enterprise management theory from scientific management to modern management, from the one-sided emphasis on the scientific management to emphasizing the combination of scientific and humane management, the traditional assessment system that originally with one-sided emphasis on being scientific has also developed to modern assessment system that emphasizes the combination of being scientific and being humane.

The main feature of modern assessment system is that it considers the purpose of performance assessment is not to assess staffs' work performance, but it also focuses on staffs' development; correspondingly, a supervisor usually has two main responsibilities: managing and coaching; the supervisor is not only the judge but also the coach (counselor); from the establishment of the assessment system, the development of assessment criteria, the self-assessment of staffs to interview between the supervisor and staffs, feedback of the assessment result, staffs' complaint to the formulation of staffs' career development plan, etc., emphasize is out on staffs' participation, development and interests. Staff performance assessment system is very important.

\section{Definition of Staff Performance Assessment}

Staff performance assessment is an evaluation of staffs' work ability, and is also called performance assessment, staffs evaluation, performance valuation and performance review.

Dong Ke believes that staff performance assessment is an institutional process to develop staffs' performance target and collect relevant information about performance, regularly assess and give feedback of staffs' completion of performance so as to improve staffs' work performance and finally improve the enterprise's overall performance. Huang Yingzhong believes that staff performance assessment is an assessment and evaluation of staffs' contribution and development potential; Berk. R.M. points out that staff performance assessment refers to collecting staffs' work materials through observation activities so as to be basis for staffs' personal decision-making; Randall believes that staff performance assessment is to measure, evaluate and affect attributes and behavioral results related to staffs work so as to find the work of staffs within an organization.

All in all, staff performance assessment refers to that enterprises or organization comprehensively evaluate staffs' work ability and work performance from time to time as the basis 
to measure and motivate staffs, and the final purpose is to ensure that enterprises and staffs can obtain the win-win result, i.e., organizations obtain profits and staffs achieve performance development.

\section{Current Assessment at Small-and-Medium-Sized Private Enterprises}

At present, small and medium-sized enterprises mainly adopt the subjective assessment methods, and the assessment is mainly carried out according to the various assessment criteria proposed by the direct supervisor or the enterprise's management department. Besides, whether an individual has its special talent or advantage, the same weight is adopted to be the basis for the salary adjustment and bonus distribution; the approach has the several following shortcomings:

Lack of fairness in assessment methods. Different attributes of the small and medium-sized private enterprises have different degrees of contribution, but the current approach uses the same weight but does not adopt different weights for groups with different attributes; at the same time, the weights between the criteria using a simple weighting method, but not the relationship between each other, so the criteria for interaction, the simple weighting method cannot get the correct performance of the total value; therefore, in the entire assessment results cannot fully reflect the fair and just results.

Assessment method is relatively simple. At present, the main assessment methods of small and medium-sized private enterprises are "target evaluation method", "scale method" and "work title method."

Lack of scientific assessment indicators. Choosing and determining staff performance assessment indicators is an important and difficult problem. The majority of small and medium-sized private enterprises often determine the performance indicators based on the experience of business leaders, and do not objectively develop the performance indicators based on the actual situation.

Assessment cycle is unreasonably set. The so-called assessment cycle refers to how long the enterprise employees conduct an assessment. The majority of small and medium-sized private enterprises' assessment cycle coincides with the staffs' salary payment cycle. This is a viable option for mission performance indicators; however, for peripheral performance indicators, it is appropriate to carry out an assessment over a relatively long period of time, such as half a year or a year. Therefore, the enterprise performance cycle should be combined with the specific reality of the enterprise.

Staff performance assessment and other work links are not closely linked. The identification of performance indicators and the results of the performance feedback at the end are key steps in the performance assessment. The premise of doing so is to consider staff performance assessment in the performance management system; most small and medium-sized private enterprises do not attach importance to performance before and after the work, which is likely to result in an independent view of employee performance assessment.

\section{Ways to Improve Staff Assessment System}

The core of "people-oriented" management is to satisfy staffs' reasonable expectation from staffs' real demand and give full play to staffs' personal value. In today's ever-changing society, companies must abandon the traditional management mode, respect staffs, consider for staffs and truly provide available resources for staffs' development. In order to improve staff training level, human resource management concept must be changed, and emphasis should be put on retaining talents, insisting on improving staff training system, which has the several following requirements:

Clarify the training and management process as well as the training target. While developing staff training plans, enterprises need to pay attention to staffs' demand and increase investment in training so as to improve the overall quality of staffs. Enterprises should also bear all the training cost, such as those courses to improve staffs' special knowledge system and labor skills. Enterprises should segment staffs and divide staff training into training for new staffs and training for old staffs. 
Training for new staffs mainly introduces the basic situation of the enterprise and relevant business knowledge so as to make new staffs get integrated in the corporate culture as soon as possible, and training for old staffs mainly emphasizes on expanding staffs' knowledge ken so as to make them better adapt to the development of the times and do a better job. Enterprises also need to develop long-term staff training plans.

Improve enterprise assessment and incentive mechanism. After the staff training, the enterprise should timely assess and test staffs so as to supervise staffs in learning. Enterprises need to train staffs' concept of partnership by taking modern incentive policy and adopt future-oriented human resource investment mechanism to enhance the company's cohesiveness and deal with the issue of authorizing staffs' innovation. Meanwhile, enterprises need to change traditional value distribution concept and integrate diversified value distribution concept into the corporate management.

Changing methods. Enterprises should constantly change the training methods, adapt to the development of the times and get out of the traditional training methods so as to make training more flexible and attractive. This can enhance staffs' interest in work. We can adopt interaction or some competitions at training class so that staffs will take the initiative to participate in training course and they will quickly and easily absorb the learned knowledge.

Training methods should be targeted. Corporate training should be targeted. They can investigate staffs and take targeted methods in training for different staffs and the carry out special training towards staffs at different levels and in different fields.

Standardize the training process. Enterprises should pay attention to the norms of training process, which is a systematic work. All departments and units within an enterprise need to assist each other, so enterprises need to establish a relatively independent training department and arrange special personnel to take charge of the training. Besides, leaders' support and cooperation of all units are needed in training.

\section{Conclusion}

In this paper, the staff performance assessment indicators and methods are suitable for some small and medium-sized private enterprises with some guiding role for other small and medium-sized enterprises. This research has the following conclusions and suggestions:

In staff performance assessment at most small and medium-sized enterprise, the assessment indicators are subjective to certain degree with much pursuit of the integrity of the assessment project; it is suggested that when small and medium-sized enterprises obtain the first assessment material, they need to timely analyze the material, delete or merge repeatable assessment indicators.

In setting various performance assessment indicators' weight, it is better to use analytic hierarchy process to conduct questionnaire survey and calculation so as to obtain relatively fair and reasonable weight distribution. Meanwhile, the weight should be changed according to time and staffs' performance, so it is necessary to regularly check its appropriateness.

In the calculation of performance assessment results, in addition to using traditional simple weighting method, it is recommended to consider other laws with the majority and the minimum opposition in order to achieve a fair and equitable performance assessment.

\section{References}

[1] Kornelakis A, Voskeritsian H. International and Comparative Human Resource Management[J]. 2015.

[2] Albrecht S L, Bakker A B, Gruman J A, et al. Employee engagement, human resource management practices and competitive advantage $[\mathrm{J}]$. Journal of Organizational Effectiveness, 2015, 2(1):7-35.

[3] Stone D L, Deadrick D L, Lukaszewski K M, et al. The influence of technology on the future of human resource management[J]. Human Resource Management Review, 2015, 25(2):216-231.

[4] Ichniowski C, Shaw K, Prennushi G. The Effects of Human Resource Management Practices on Productivity: A Study of Steel Finishing Lines[J]. American Economic Review, 1997, 
87(3):291-313.

[5] Becker B E, Gerhart B. The Impact of Human Resource Management and Organizational Performance[J]. Academy of Management Journal, 1996, 39(4):779-801.

[6] Stone D L, Deadrick D L. Challenges and opportunities affecting the future of human resource management[J]. Human Resource Management Review, 2015, 25(2):139-145.

[7] Ichniowski C, Shaw K, Prennushi G. The Effects of Human Resource Management Practice on Productivity[J]. American Economic Review, 1995, 87.

[8] Wart M R V, West J P, Bowman J S, et al. Human Resource Management in Public Service: Paradoxes, Processes, and Problems 5ed[J]. 2015.

[9] Lange A H D, Kooij D, Heijden, B.I.J.M. van der. Human resource management and sustainability at work across the lifespan: An integrative perspective[J]. 2015.

[10]Wordsworth R. Principles of Human Resource Management[J]. 2015.

[11]Björkman I, Welch D. Framing the field of international human resource management research[J]. The International Journal of Human Resource Management, 2015, 26(2):136-150.

[12] Obeidat B, Al-Sarayrah S, Tarhini A, et al. Cultural Influence on Strategic Human Resource Management Practices: A Jordanian Case Study[J]. International Business Research, 2016, 9(10):94-114. 